\title{
RETRACTED ARTICLE: COVID 19 response: An analysis of teachers' perception on pedagogical successes and challenges of digital teaching practice during new normal
}

\author{
Arnab Kundu $^{1}$ (D) $\cdot$ Tripti Bej ${ }^{2}$
}

Received: 16 January 2021 / Accepted: 10 March 2021/Published online: 18 April 2021

(C) The Author(s), under exclusive licence to Springer Science+Business Media, LLC, part of Springer Nature 2021

The Editor-in-Chief has retracted this article because it overlaps with an unpublished manuscript by different authors that was submitted to another journal. The unpublished manuscript was submitted to the other journal before this article was submitted to Education and Information Technologies. Tripti Bej disagrees with this retraction. Arnab Kundu agrees with this retraction.

The online version of this article contains the full text of the retracted article as Supplementary Information.

Electronic supplementary material The online version of this article (https://doi.org/10.1007/s10639-02110503-5) contains supplementary material, which is available to authorized users.

Arnab Kundu

arnabkundu5@gmail.com

Tripti Bej

tapubej@gmail.com

1 Bankura University, Bankura, West Bengal, India

2 Srima Balika Vidyalaya, Paschim Midnapore, West Bengal, India 